\title{
A EXPERIÊNCIA DE SER ESTUDANTE INTERNACIONAL: DISCURSOS, PRÁTICAS NARRATIVAS E APRENDIZAGENS EM DIÁLOGO
}

\author{
LILIAN UCKER PEROTTO \\ Universidade Federal de Goiás
}

RESUMO

Neste artigo, compartilho reflexões desenvolvidas em minha tese de doutorado sobre a relação da experiência de ser estudante internacional, em Barcelona, e a internacionalização do ensino superior, fenômeno este que tem provocado discussões a respeito do papel que assume hoje a universidade, na economia mundial, e as consequências de se pensar e tomar a internacionalização como meta para o sistema educativo. Para este artigo, narro como as cartas tornaram-se o modo como organizo o relato da tese, apresentando e problematizando, em seguida, os relatos biográficos dos colaboradores da pesquisa, a partir do discurso da internacionalização do ensino superior.

Palavras-chave: Pesquisa narrativa. Internacionalização do ensino superior. Estudante internacional e cartas.

LA EXPERIENCIA DE SER ESTUDIANTE INTERNACIONAL: DISCURSOS, PRÁCTICAS NARRATIVAS Y APRENDIZAJES EN DIÁLOGO

En este artículo comparto reflexiones desarrolladas en mi tesis de doctorado sobre la relación de la experiencia de ser estudiante internacional en Barcelona y la internacionalización de la enseñanza superior, fenómeno que ha provocado discusiones sobre el papel que asume hoy la universidad en la economía mundial y las consecuencias si se piensa y toma la internacionalización como meta para el sistema educativo. Para este artículo, narro cómo las cartas se convirtieron en el modo en que organizo el relato de la tesis, presentando y problematizando a continuación, los relatos biográficos de los colaboradores de la investigación a partir del discurso de la internacionalización de la enseñanza superior.

Palabras-clave: Investigación narrativa. Internacionalización de la enseñanza superior. Estudiante internacional y cartas. 


\section{ABSTRACT THE EXPERIENCE OF BEING AN INTERNATIONAL STUDENT: SPEECHES, NARRATIVE PRACTICES AND LEARNING IN DIALOGUE}

In this article, I share the reflections developed in my doctoral thesis about the relationship between the experience of being an international student in Barcelona and the internationalization of higher education, a phenomenon that has provoked discussions about the university's role in the world economy today and the consequences of thinking and taking internationalization as a goal for the education system. For this article, I narrate how letters became the way I organize the thesis report, presenting and then problematizing the biographical reports of the research collaborators in reference to the discourse on the internationalization of higher education.

Keywords: Narrative inquiry. Internalization of higher education. International student and letters.

Recuerdo perfectamente el día en que volví a Barcelona para, por fin, empezar el doctorado. Era un 18 de octubre de 2006 y el cielo gris de la tarde acompañado de una fina lluvia que se diluía junto a un clima típico de invierno, marcaba una nueva etapa en mi vida: finalmente el sueño de vivir en otro país se iba a realizar. Hablar del primer día en el nuevo hábitat, me trae cierta melancolía. El día que llegué sigue estando con más fuerza en la memoria que el día que volví a Brasil.

La imagen que me viene a la cabeza de aquel momento fue, que al coger mis maletas y salir por la puerta de desembarque, observé las personas aguardando a sus seres queridos; emocionados y abrazándose me di cuenta que estaba completamente sola, que no había nadie esperándome. La sensación de sentirme sola en aquel momento me hacía pensar en "la incertidumbre respecto al futuro, la fragilidad de la posición social y la inseguridad", elementos que en general forman parte de la vida "en el mundo de la modernidad líquida" (BAUMAN, 2006, p. 30). Nóvoa explica que nos encontramos en la actualidad en una época caracteri- zada por la toma "de conciencia de nuestras limitaciones para interpretar y encontrarle sentido a las complejidades del mundo. Sabemos que necesitamos plantearnos nuevas preguntas, buscar significados diferentes, imaginar otras historias" (2003, p. 61). En esto sentido, estudiar en Barcelona suponía buscar nuevos significados y aprendizajes en mi vida, pero también la incertidumbre del futuro.

En Barcelona, pasé a preguntarme constantemente: ¿Qué nos hace salir de nuestro país para vivir en otro? ¿Qué significa entrar en otro idioma? ¿Qué significa vivir en otro país? ¿Qué significa estar lejos de la familia, de los amigos? ¿Somos conscientes de la importancia y los desafíos que asumimos al decidir estudiar en otro país? Después, pasé a creer que tales cuestionamientos, aunque personales, podrían ayudar en la construcción de mi proyecto de doctorado, donde la noción de 'student transition' (HELLSTÉN, 2008), y, por eso, la 'experiencia de ser estudiante internacional', serían centrales para la investigación.

Sin embargo, al hablar del tema 'experiencia de ser estudiante internacional', fue inevi- 
table no acercarme del fenómeno que la generaba, la movilidad estudiantil, consecuencia, esta vez, de la Internacionalización de la Enseñanza Superior, que, por cierto, ha estado en el centro de los debates de las instituciones de enseñanza superior en diferentes países. Este fenómeno ha provocado discusiones sobre el papel que asume hoy la universidad en la economía mundial y cuáles son las consecuencias de pensar y tomar la internacionalización como meta para el sistema educativo.

Frente a eses desafios - de reflexionar sobre los efectos de la internacionalización de la enseñanza superior a partir de los relatos biográficos de estudiantes brasileños en Barcelona - que desarrollé mi tesis de doctorado en el programa de posgrado en Arte y Educación de la Universidad de Barcelona (España). Mi investigación trató de investigar cómo se ha constituido el sentido de ser estudiante internacional de nueve colaboradores - Alice, Rodrigo, Lucas, Bia, Marta, Gerson, Rafaela, Elvira e Ana Terra - 6 mujeres y 3 hombres, con edad entre 28 y 46 años cuando entrevistados en 2008 y 2009. A través de la pregunta central: ¿por qué es importante y necesario pensar en las pedagogías y prácticas que tengan en cuenta el contexto internacional?, propuse conocer para luego comprender lo que decían los estudiantes brasileños sobre sus experiencias como estudiantes en la Universidad en Barcelona.

Desde una perspectiva narrativa de investigación, la tesis fue organizada a través de siete cartas. Además de funcionar como un recurso ficcional, las cartas fueron espacios de diálogo e interlocución en el que el investigador se relaciona con otros personajes, los destinatarios de las cartas (tribunal de la tesis doctoral, amigas, Meeri Hellstén, colaboradores de la investigación, los futuros estudiantes internacionales y el director la tesis doctoral), enseñándoles escenas y acontecimientos que se configuran importantes para el problema de la tesis, y que promovieron así un espacio tiempo singular de construcción de la subjetividad entre la investigadora y los colaboradores de la investigación.

En esto artículo, les contaré como las cartas llegaron a ser el modo cómo organizo el relato de la tesis, destacando algunos tránsitos y referencias que me ayudaron a configurar mi trabajo a través de cartas, permitiendo que yo como investigadora también pudiese inscribirme en el texto científico y así reinventarme en la y por la escrita cotidiana. (IONTA, 2011). A seguir, trato de hacer un paralelismo en el artículo, entre lo que 'dice' el discurso de la internacionalización de la enseñanza superior y lo que 'dicen' los colaboradores sobre la experiencia de ser estudiante. Pensar la universidad como un espacio de acogimiento y el concepto de 'aprender' nace después del paralelismo de dichos discursos, el de la internacionalización y el de los colaboradores de la investigación.

Antes de avanzar en la discusión que propongo, es importante señalar que, así como hago en la tesis doctoral, intercalo el castellano y el portugués en este artículo. En la tesis cada carta fue escrita y pensada conforme el idioma del destinatario, pero la idea de escribir una tesis multilingüe no surgió en el momento que decidí escribir la tesis en forma de cartas. Utilizar el castellano y el portugués nacía de la necesidad de pensar que la identidad es cambiante, que nos formamos a partir de muchas relaciones, y que el sujeto es el resultado del cruce dinámico de múltiples elementos culturales. Más tarde, junto con los relatos de los colaboradores - con los innumerables textos subrayados en diversos idiomas-, percibí que no podría dejar nuestras experiencias, la mía y la de los sujetos colaboradores, de lado; porque como explica Walker y Chaplin (2002, p. 46) "nosotros [no solo] hablamos len- 
guas, las lenguas también - en cierto - nos hablan. Es decir, que una vez existe un sistema de representación, éste condiciona el modo como percibimos y pensamos el mundo" y, en este caso, como construimos y representamos nuestras investigaciones.

\section{Uma tese biográfica-narrativa escrita em forma de cartas}

Quando iniciei o doutorado, o tema da tese ainda era bastante incipiente. Cheguei a Barcelona com a ideia de trabalhar com histórias de vida, a partir da ideia dos deslocamentos geográficos. Inicialmente, meu foco centrava-se em uma pesquisa exclusivamente autobiográfica. Naquele momento, ainda me sentia bastante influenciada pela pesquisa desenvolvida durante a realização do meu mestrado em cultura visual no Brasil. Tal pesquisa tinha como foco compreender e analisar como estudantes de escolas públicas se relacionavam com o espaço escolar e também como o imaginavam. Hoje, com um olhar mais crítico sobre a investigação desenvolvida, percebi que pouco contei da minha relação com os espaços escolares vividos na infância e meus deslocamentos entre cidades e estados brasileiros. Ao relê-la, senti a necessidade de retomar certas questões: uma delas centrava-se nas aprendizagens que cada espaço teria me oportunizado, seus limites e, de alguma maneira, as subjetividades que se produziram nos e pelos espaços.

Outra questão buscava perceber as mudanças durante esses deslocamentos geográficos, a partir de novos marcos epistemológicos. Mas estas questões e inquietações surgiram depois que tive a oportunidade de estar em Barcelona, durante dois meses, para cursar algumas disciplinas do doutorado. Naquela época, em 2005, eu ainda era estudante de mestrado. A investigação ainda não estava concluída, mas naquela ocasião eu não era consciente da necessidade ou da importância de expor meus trânsitos e minha relação com o tema da pesquisa, neste caso, com o espaço escolar.

Assim, trouxe todas essas inquietações em minha "bagagem" para Barcelona, e, aos poucos - vivendo e experimentando a posição de estudante internacional, nas suas mais diversas situações, seja em busca de trabalho, de apartamento para compartilhar, na relação com a instituição universitária ou ainda no encontro com os idiomas, passei não só a acreditar na importância de discutir a respeito do que Hellstén fala sobre "student transition experience" (2007), mas principalmente saber o que outros estudantes contavam sobre suas experiências como estudantes em Barcelona.

Fui pouco a pouco construindo uma relação com o tema, a partir de diálogos com os colaboradores, autores e com aqueles que se mostravam interessados no que vinha pesquisando. Em 2009, meu deslocamento entre Brasil e Espanha tornou-se intenso, já que fui aprovada em um concurso público, em uma Universidade Federal brasileira. Tal situação fez com que minha dedicação à tese ficasse em suspenso. Passados alguns anos depois do meu retorno ao Brasil, entregue a uma docência intensa e a práticas que não envolviam necessariamente o tema de minha pesquisa, percebi que precisava de dedicação exclusiva para avançar e assim finalizar a tese de doutorado.

Ao concluir meus três anos de estágio probatório, solicitei uma "dispensa" para estar em Barcelona e por fim finalizar a tese. Ao chegar na cidade, pensei que, em algumas semanas, já estaria concentrada e escrevendo. Esqueci por alguns momentos que teria que me readaptar, novamente, não só ao cotidiano da cidade, aos horários, mas principalmente recuperar o "ritmo" e a "dedicação" à tese, os quais eu havia perdido havia muito tempo. 
Passaram-se dias, semanas, meses, e o ritmo não chegava. Foram muitas as tentativas para avançar na escrita. Criei um blog, reli as entrevistas realizadas com os estudantes colaboradores, retomei leituras, rascunhos. Mas, naquele momento, absolutamente nada me fazia avançar. Certo dia, decidi escrever uma carta ao orientador da tese para explicar-lhe os desafios que vinha enfrentando e as possíveis estratégias que pensava utilizar para desbloquear a escrita e minha relação com ela. Quando finalizei a carta, tive dúvidas se enviava ou não, porque, afinal de contas, a sala onde eu trabalhava, estava localizada ao lado da sala do diretor de tese. Parecia mais fácil procurá-lo pessoalmente. No entanto, me sentia mais cômoda escrevendo uma carta. Pela manhã, ao despertar, fui surpreendida por uma carta-resposta do orientador. 0 diálogo estabelecido e a imediatez de sua resposta, naquele momento, levaram-me a imaginar a escrita de outras cartas para outros destinatários. Logo me perguntei: se consigo escrever cartas, mas não a tese, porque não escrever uma tese em forma de cartas?

Antes de apresentar a proposta ao orientador - de uma tese escrita em formato cartas - enumerei algumas razões que me levavam a tal decisão. A primeira delas foi recordar que, como estudante de doutorado, as cartas foram utilizadas inúmeras vezes como estratégia para me comunicar e me aproximar de um público que eu vinha pesquisando. Escrevi cartas para apresentar em seminários, para participar de disciplinas e até mesmo para a instituição em que atuo como professora, quando finalmente solicitei um afastamento para dedicação à tese doutoral. Logo, recuperei, na memória, a relação que construí com as cartas quando passei a colecioná-las na infância. Além disso, a exposição organizada pela artista francesa Sophie Calle, a partir de uma carta de ruptura de seu ex-noivo, e os inúmeros livros publica- dos por Paulo Freire, em formato carta, também serviram como inspiração para justificar a escolha do formato da tese.

As cartas nasciam de uma situação de crise, mas também como uma possivel "solução" para meu avanço na escrita. A sensação era que finalmente eu começava a assumir minhas subjetividades. Como argumenta Porres, "no hay relato, continúa, si el sujeto de la acción no asume su subjetividad"1 (2012, p. 29). Naquele momento, eu era o sujeito da ação, e tinha que "hacer hablar" todo o aprendido durante os anos, dando conta de um percurso de investigação que havia iniciado há muito tempo atrás. A subjetividade, como explicam Guattari e Rolnik, no livro Cartografias do desejo, é produzida quando nos encontramos com o outro. O outro é aqui compreendido, não só como uma pessoa, mas como o outro-ação, o outro-natureza, o outro-social, e também como o outro-processo, o outro-carta. A subjetividade como aquela que não "é passivel de totalização ou de centralização no indivíduo" (GUATTARI; ROLNIK, 2011, p. 31); é produzida ou fabricada através de componentes éticos, históricos e sociais. Em certos momentos, é reinventada e, por isso, movimenta o sujeito que não é um ser previamente definido, mas se constrói à medida que se relaciona com o mundo.

Neste sentido, escrever cartas era um exercício "sobre si mesmo, em favor de uma escrita menos automática, menos servil, menos utilitarista; em favor de uma escrita transgressora" (FISCHER, 2005, p. 132). Para Machado (2004, p. 1), "na maioria das vezes a escrita 'científica' deixa poucos rastros das inúmeras implicações que a teceu". As incertezas, as dúvidas, ou ainda "as noites mal dormidas, as páginas em branco na tela do computador ficam para trás compondo uma memória que se quer es-

1 "não há história, continua, se o sujeito da ação não assume sua subjetividade". 
quecida ou uma ferida que se quer cicatrizada ou uma espécie de diário de erros superados", como relata Machado (2004. p. 1). A escrita como um "elemento vital" (CAHNMANN-TAYLOR; SIEGESMUND, 2008, p. 51), em um relato de investigação, é também um desafio político e ético, já que seu papel, como explica Foucault, no texto A escrita de si, é

Constituir, com tudo o que a leitura constituiu um 'corpo' (quicquid lectione collectum est, stilus redigat in corpus). E, este corpo, há que entendê-lo não como um corpo de doutrina, mas sim - de acordo com a metáfora tantas vezes evocada da digestão - como o próprio corpo daquele que, ao transcrever as suas leituras, se apossou delas e fez sua a respectiva verdade: a escrita transforma a coisa vista ou ouvida 'em forças e em sangue' (in vires, in sanguinem). Ela transforma-se, no próprio escritor, num princípio de ação racional. (FOUCAULT,1992, p. 141).

A escrita da minha tese de doutorado, foi tomada, portanto, como um processo em trânsito, e em diálogo com outro(s). Como investigadora, formei parte do contexto, interagi com outros, e também transformei-me em sujeito da investigação, porque a escrita, como explica Luce-Kapler, é "um site de possibilidade onde podemos aprender coisas sobre nós mesmos, onde imaginamos escolhas diferentes e onde reconfiguramos nossa experiência" (2004, p. 103). As cartas representaram um "espaço-tempo singular de conhecimento de si" (RIBEIRO; SOUZA, 2010, p. 91), um recurso através do qual as narrações se converteram "en una construcción y reconstrucción narrativa compartida" ${ }^{2}$ (CONNELLY; CLANDININ, 1995, p. 23). Além de possibilitar a revisão de uma série de conceitos e posturas conformadas desde "una verdad impersonal, desapasionada y abstracta generados por las prácticas de investigación revestidas de un excluyente discurso académico"3 (HERNAN-

2 "em uma construção e reconstrução narrativa compartilhada".

3 "uma verdade impessoal, desapaixonada e abstrata
DEZ; RIFÁ, 2011, p. 27), as cartas transformaram o conhecimento produzido na pesquisa, aliando "forma e conteúdo". Isso quer dizer, que além de ter sido forma atraente para estudar e representar a experiência dos estudantes internacionais (PINNEGAR; DAYNES, 2007), possibilitaram também um modo de conhecer e pensar naquilo que Bruner (1986) chama de "narrativo", não podendo ser reduzidas ou compreendidas através de categorias generalizáveis. Neste sentido, a pesquisa narrativa, como um processo colaborativo que "conlleva una mutua explicación y re-explicación de histórias a medida que la investigación avanza"4 (CONNELLY; CLANDININ, 1995 , p. 21), permitiu aproximar-me dos relatos dos estudantes brasileiros, para compreender quais eram os efeitos de viver e estudar em um país estrangeiro, e, consequentemente, como isso impactava seus modos de ser e estar no mundo.

Para tratar do tema que proponho neste artigo, tomo como referência algumas reflexões desenvolvidas na tese de doutorado direcionadas a dois destinatários das cartas: a professora e pesquisadora Meeri Hellstén e futuros estudantes internacionais. Na carta que dedico à professora e pesquisadora Hellstén, problematizo algumas situações vividas por mim, em relação à internacionalização do ensino superior, no contexto brasileiro, e logo sobre a importância e a necessidade de pensar em pedagogias internacionais. É nesta carta que os colaboradores da investigação contam suas experiências como estudantes na universidade. De certa forma, faço um paralelo entre o que "diz" o discurso da internacionalização e o que os "colaboradores" dizem ou não dizem sobre a experiência de ser estudante. Já na carta que dedico aos futuros estudantes internacionais,

geradas por práticas de investigação revestidas de um discurso acadêmico excludente".

4 "envolve uma explicação mútua e uma reexplicação das histórias à medida que a investigação avança". 
a experiência de ser estudante brasileiro, em Barcelona, as dificuldades de viver em um país estrangeiro, as condições de viver, morar e se comunicar, e a noção do aprender são temas que emergem não só das entrevistas realizadas com os colaboradores, mas também das imagens/músicas compartilhadas por eles/elas.

\section{O discurso da internacionalização do ensino superior e o relato dos estudantes brasileiros}

Quando defini que escreveria cartas e não capítulos, Meeri Hellstén foi a primeira destinatária a ser escolhida. Eu tinha muito o que the contar. Conheci Meeri, em Barcelona, quando ainda definia meu objeto de estudo. Era 2008 e nosso encontro se deu devido a uma parceria entre a universidade australiana, em que Meeri atuava, e a universidade em que eu estudava (HELLSTÉN; UCKER PEROTTO, 2017). Através de seus textos, que defendem "abordagens culturalmente sensiveis" (HELLSTÉN; REID, 2008, p. 2) em relação às práticas da internacionalização, que chegaram as primeiras contribuições a minha tese de doutorado.

As primeiras leituras já apontavam que o termo “internacionalização do ensino superior" não era novo, mas a dimensão que certo fenômeno estava provocando, não só nas instituições, mas também na vida das pessoas, se podia dizer que era recente, principalmente no Brasil, onde pouco a pouco o tema ganhava destaque. Uma das explicações para o fenômeno está “relacionada ao próprio aumento da mobilidade estudantil internacional" (LIMA; CONTEL, 2011, p. 82). Segundo dados da OECD (Organização para a Cooperação e o Desenvolvimento Econômico), no ano de 2000, existiam aproximadamente 2 milhões de alunos de terceiro grau estudando fora de seus países de origem, e no ano 2010 registraram-se 4 milhões.
Apesar do caráter internacional das universidades estar presente desde a Idade Média, com a criação das primeiras instituições que consideravam o conhecimento um bem universal e tinham como característica intrínseca serem internacionais (LIMA; CONTEL, 2011), é a partir das últimas décadas que passamos a perceber o interesse em investimentos em relação a este novo mercado que começa a movimentar milhões de dólares, em todo o mundo, se tornando, para alguns países, como os Estados Unidos, um grande negócio (ALTBACH, 2004). Só neste país, os estudantes estrangeiros contribuem com aproximadamente 12 milhões de dólares por ano. Para Hellstén e Reid, nos últimos 20 anos, passamos a testemunhar:

uma incrivel ampliação das oportunidades de mobilidade que tem permitido que estudantes e professores participem de uma experiência internacional de ensino superior. Hoje, os efeitos da globalização são inegavelmente evidentes em todos os aspectos do ensino superior [...]. (HELLSTÉN; REID, 2008, p. 1)

Nesta "nova geopolítica do conhecimento" (LIMA; CONTEL, 2011), as nações passam a interagir impondo regras, criando um mercado, mas também demonstrando interesses distintos. Por isso, o quadro da internacionalização vai se moldar:

em função do comportamento de cada nação, se de forma mais ativa ou se mais passiva: enquanto alguns países do centro do sistema mundo assumem papéis mais protagonistas, a maioria dos demais se insere por uma relação de subordinação. (LIMA; CONTEL, 2011, p. 19)

Entre protagonismos e subordinações, nações ativas e passivas, Mello (2011) comenta que, atualmente, também são utilizadas expressões como "exportação" e “importação", no que se refere à internacionalização do Ensino Superior. Neste caso, os termos são utilizados "segundo a qualidade da participação de países ou regiões no movimento de troca 
dos serviços educativos transfronteiriços" (MELLO, 2011, p. 37), referindo-se às nações exportadoras, as mais desenvolvidas, e no caso das importadoras, os países pobres ou em vias de desenvolvimento. No entanto, ele chama a atenção para o fato de que não podemos reduzir os termos "exportar" e "importar" a "fluxos binários", como se a "Educação Superior" assumisse as mesmas formas "de dinâmica e configuração", nos mesmos lugares, já que, como afirmam Lima e Contel (2011), esta configuração dependerá do conjunto de iniciativas dos Estados nacionais, assim como dos objetivos que cada nação queira alcançar.

Vale a pena esclarecer que a internacionalização surge como consequência dos efeitos da globalização, ou seja, de uma "realidade formada por uma economia mundial cada vez mais integrada [...]", já a internacionalização reage através de uma "variedade de políticas e programas que as universidades e os governos implantam para responder a globalização" (ALTBACH; REISBERG; RUMBLEY, 2009, p. 7). Globalização e internacionalização criam então um mercado educacional, mas também cidadãos de todo o mundo, com novos conhecimentos, novas habilidades e atitudes que thes permitem atuar de maneira eficaz em um meio global, internacional e multicultural. Formar estudantes estrangeiros, como afirmam Lima e Contel (2011):

[...] seja na graduação ou na pós-graduação, nos países de centro, auxilia também no processo de expansão dos laços econômicos, desses com os países de origem dos estudantes estrangeiros; boa parte destes estudantes, na volta a sua terra natal...se tornam uma espécie de embaixadores dos interesses das nações que os abrigaram, por carregar um conteúdo de valores, comportamentos e atitudes políticas adquiridas no período de estudos no exterior [...]. (LIMA; CONTEL, 2011, p. 83)

Em um artigo amplamente publicado e traduzido para vários idiomas, Jane Knight (2012) trata de explicar cinco verdades sobre a internacionalização. Uma delas é o fato de que a internacionalização não é um fim em si mesma, mas um meio para um fim. Trata-se, conforme a autora, de um "truísmo frequentemente mal interpretado que pode levar a um entendimento enviesado daquilo que a internacionalização pode ou não pode fazer". Para De Wit (2011), é equivocado pensar na internacionalização como algo que tem um objetivo em si mesmo ou acreditar que, conforme o autor, "la internacionalización significa tener muchos estudiantes internacionales"5 (DE WIT, 2011, p. 82). Para Knight, ao invés de associarmos a internacionalização com um currículo mais internacionalizado ou ainda com um aumento da mobilidade acadêmica por si mesma, poderíamos garantir que através da internacionalização “[...] os estudantes estejam mais preparados para viver e trabalhar num mundo mais interconectado [...]" (KNIGHT, 2012).

Hellstén (2007) chama a atenção para as questões e os aspectos socioculturais da prática pedagógica universitária, a partir do ponto de vista do estudante internacional. Para a autora, questões como qualidade de ensino, avaliação, currículo e integração cultural deveriam fazer parte das discussões que rondam o contexto internacional da Educação Superior. O aumento do número de matrículas de estudantes internacionais na Austrália e, consequentemente, a dependência e a importância da presença do estudante estrangeiro para o sistema australiano de Educação Superior (LIMA; CONTEL, 2011) passaram a inquietar pesquisadores e, neste caso, os professores que atuam em universidades do país passaram a levar em consideração, principalmente, "os efeitos pedagógicos da aprendizagem internacional" (HELLSTÉN, 2008). Para Hellstén (2008, p. 83), este é um dos desafios do novo século:

5 “a internacionalização significa ter muitos estudantes internacionais". 
a promoção de uma aprendizagem eficaz que leve em conta o contexto e a dinamicidade dos tempos globais, já que "os estudantes do novo milênio são cidadãos globais que veem suas futuras oportunidades além dos limites de sua nação e suas perspectivas profissionais fora dos parâmetros definidos localmente" (HELLSTÉN, 2008, p. 83). Vindo de encontro a este pensamento, Lee (2013, p. 85$)$ destaca que alguns elementos da internacionalização têm sido pouco considerados, como "o aspecto humano da migração e da troca". Ao invés disso, a discussão ainda está centrada na relação de entrada e saída, ou seja:

Uma abordagem quantitativa pautada pelos números, em lugar de uma abordagem orientada pelos resultados. Além disso, o discurso dedicou pouca atenção às normas, valores e princípios éticos da prática da internacionalização. A abordagem tem sido demasiadamente orientada de maneira pragmática, preocupada com o cumprimento de metas, sem que haja um debate envolvendo os riscos potenciais e as consequências éticas. (LEE, 2013, p. 71)

É importante salientar que o estudante internacional, nem sempre é consciente de que faz parte da "lógica do mercado do Ensino Superior" (MELLO, 2011). Apesar do conhecimento ser considerado "o motor da nova ordem global e principal vetor da dinâmica econômica" (MELLO 2011, p. 53), muitos dos estudantes justificam sua escolha, a partir daquilo que De Wit (2010) chama de categoria social/ cultural. As razões de ordem social e cultural têm a ver com "o papel que as universidades e sua pesquisa e ensino podem desempenhar na criação de uma compreensão intercultural e uma competência intercultural para os alunos e para suas pesquisas" (DE WIT, 2010, p. 9). Além disso, relaciona-se com o fato de "que o indivíduo, o aluno e o acadêmico, ao estarem em um ambiente internacional, se tornem menos provinciais" (DE WIT, 2010, p. 9).
Quando questionados durante a entrevista, o porquê de estudar em um país estrangeiro e logo em Barcelona, alguns colaboradores da pesquisa reconhecem que estudar em outro país ajudaria no seu crescimento profissional, ao regressarem para o Brasil, mas que também seria uma oportunidade de ampliar as experiências de mundo. Gerson e Marta, dois colaboradores da pesquisa, escolheram Barcelona para cursar o doutorado porque tinham uma amiga vivendo na cidade. Além disso, Marta comentou que sempre teve "a ideia de morar em Barcelona, morar fora, morar no exterior, e principalmente em algum país de língua espanhola, para poder ter essa experiência de viver fora e de falar espanhol todo dia". Ana Terra, uma colaboradora formada em Psicologia, contou-me, durante nossa entrevista, que não foi a Barcelona por acaso. Influenciada por duas amigas, que tinham conseguido uma bolsa de estudos para vir a Barcelona estudar, Ana também resolveu tentar, mesmo pensando que não conseguiria. Muito próxima de suas amigas de faculdade, percebeu que cada uma foi tomando um rumo e que ela precisava também "colocar uma pimenta na vida". Decidida a mudar de cidade, tentou primeiramente Londres e Madrid, porque, como ela explica, "eu ficava pensando vou vir pra Barcelona e ser incapaz de falar catalão", mas Londres e Madrid foram descartadas como cidades para realizar os estudos do doutorado. No caso de Londres, foram dois os motivos que a fizeram desistir: primeiro que a universidade com a qual entrou em contato trabalhava com metodologia quantitativa, e Ana Terra acreditava que sua pesquisa não repercutiria bem no Brasil, já que o tema tinha relação com a violência doméstica. O segundo motivo da desistência de estudar em Londres tinha a ver com a dificuldade que iria encontrar para manter-se economicamente na cidade, mesmo com bolsa. Madrid surgiu como possibilidade, por influência de uma 
professora do Brasil, que havia estudado na capital espanhola, mas esta mesma professora, sua orientadora do mestrado, também sugeriu Barcelona, pois havia feito seu pós-doutorado na Universidade de Barcelona e, por isso, lhe forneceu o contato. Ana Terra acabou se decidindo pela cidade, tanto pela influência de sua professora como pela presença de suas já amigas que viviam na cidade.

Ao relacionar as justificativas dos colaboradores do porquê cursar uma pós-graduação no exterior às categorias sugeridas por De Wit (2010), a categoria acadêmica seria a motivação inicial dos estudantes, como identificou Ana Terra. Tal categoria, como explica De Wit (2010), refere-se ao aspecto internacional da pesquisa, do ensino e da instituição. É neste grupo que o estudante desenvolve e expande seu horizonte acadêmico.

No entanto, percebi que quando narravam suas experiências, os estudantes pouco contavam de sua experiência acadêmica. 0 curioso é que, quando os entrevistava, não me dei conta de que transitávamos entre os mais variados temas da vida de um estudante estrangeiro, mas que a "universidade", motivo pelo qual trazia estes estudantes a Barcelona, ficava em um segundo plano.

No início, quando pensava na expressão "experiência acadêmica", relacionava-a imediatamente com o aprender na universidade, nas aulas, nos livros e com os colegas. Meu olhar voltava-se para um espaço fechado, como se só aprendêssemos entre as quatro paredes de uma sala de aula. Eu sabia que não era assim, e minha pesquisa de mestrado (UCKER, 2006) ensinou que aprendemos nos relacionando com o mundo, com os outros e com todos os tipos de espaços, sejam eles reais ou imaginários. Talvez neste momento algumas leituras pudessem estar me influenciando: números, dados estatísticos, reformas políticas e o discurso de uma internacionalização do
Ensino Superior que está mais pautada na obtenção de um resultado (DE WIT, 2013, p. 71). Foi preciso levar em consideração que, apesar da universidade "continuar a ser o lugar dos cruzamentos, da mútua exposição da diversidade, da interpelação recíproca dos saberes", e ainda o lugar onde todo e qualquer conhecimento pode ser trabalhado e discutido, ao mesmo tempo, não era "mais o lugar hegemônico da produção do conhecimento" (GAZZOLA, 2006, p. 52). Neste caso, Gazzola (2006, p. 51) explica que "outras instituições, outras organizações, outras instâncias" também produzem conhecimentos, o que Elvira, uma das estudantes colaboradas desta tese, expressa claramente em seu relato. Apesar do doutorado ter um significado importante na vida da doutoranda, ela confessou, durante nossa entrevista, que se eu perguntasse sobre alguma recordação do tempo em que ela realizava as disciplinas no primeiro ano do doutorado, certamente não recordaria de nada, porque, para ela:

"[...] foi como um serviço militar, era obrigatório fazer isso e pronto. Para mim o extraclasse, as tardes no Ovelha, no Hard Rock, as tardes na praça Catalunha sentada comprando as cervejas dos Paquis e conversando.... Eu acho que se aprendia muito mais nesses momentos, na área de psicologia. Se aprendia muito mais do que aprendia em classe [...]". (Elvira)

Foi importante reconhecer que, apesar do pequeno espaço dado à universidade durante as entrevistas, a instituição faz parte do cotidiano dos colaboradores, apesar dos poucos vínculos criados. Lucas, por exemplo, trouxe as palavras "atitude" e "nova postura", para qualificar sua experiência em Barcelona. No caso dele, que havia realizado todos os estudos (licenciatura, especialização e mestrado) na mesma instituição, a mudança de instituição mexeu muito com ele: "ao mesmo tempo em que parece que puxa o teu tapete, porque te desconstrói em muitos aspectos, mas daí tu 
começa a te reconstruir a partir de outra perspectiva, de outro olhar [...]". Ele ainda assinala que foi uma experiência construtiva.

No caso de Gerson, a universidade the proporcionou "uma abertura de cabeça". Como ele mesmo comenta: "eu estava precisando estudar, foi uma reciclagem muito interessante". Ele destaca ainda que "três disciplinas de todas as que eu fiz que realmente me deram formação, um domínio que eu sempre tive curiosidade de saber". O estudante, que veio fazer doutorado em arquitetura, contou que, em seu primeiro ano em Barcelona, se dedicou a estudar, a ler, a conhecer a cidade. Tudo isso porque havia reservado um recurso para estar mais tranquilo no momento inicial em Barcelona. Ele comenta que resolveu, junto com a esposa, também doutoranda em arquitetura, colocar o "pé no freio", ao chegar à capital catalã. Eles vinham de uma jornada dura e estressante na cidade em que viviam no Brasil. Ele era professor de desenho, geometria e ainda desenvolvia uma atividade amadora, como artista plástico, no Brasil. Do ponto de vista intelectual, conforme ele, estudar em Barcelona "foi uma abertura de cabeça. Você sai de uma província e vem para uma metrópole. Claro que descobre que aqui tem uma série de coisas que não são muito diferentes de onde você estava, mas você tem que fazer esse trânsito para poder descobrir".

Sobre sua experiência com a universidade, Bia também avaliou positivamente. Durante o ano que ficou em Barcelona, participou de reuniões de um grupo de investigação que contribuiria com a pesquisa que vinha desenvolvendo no Brasil. Ao final, definiu sua experiência como "maravilhosa".

Alice, que nasceu na Argentina, mas que com três anos foi morar no Sul do Brasil, contou que quando foi a Barcelona, chegou com vontade de estudar, diferentemente de quando se mudou para o Rio de Janeiro, para fazer seu mestrado, quando seu maior desejo era mudar de cidade. Sobre a experiência na universidade em Barcelona, Ana relata que começou a "viver mais a vida acadêmica", mesmo que no Rio de Janeiro tivesse trabalhado como professora em uma universidade.

Durante as entrevistas, os estudantes enfatizam a importância da experiência de viver ou ter vivido em Barcelona, o que vai desde o aprender a ser mais tolerante com a diversidade cultural, como explicou Rafaela, dar valor às coisas simples do cotidiano, como limpar a casa e ter mais responsabilidade com as tarefas domésticas, no caso de Elvira, ou ainda ser mais simples com as coisas da vida, como explicou Marta.

Barcelona, sem dúvida, foi a protagonista dos relatos dos estudantes. Dos seus encantos, com atrativos culturais e condições de bem-estar social, também ganharam destaque as condições de morar e trabalhar na cidade. Rafaela definiu sua experiência em Barcelona como "uma luta de sobrevivência", e esta expressão tem relação direta com a questão de manter-se economicamente na cidade para seguir seus estudos. Lucas chegou à cidade cheio de expectativas. Esperava ficar em Barcelona pelo menos um ano. Frustrado, sem perspectiva de conseguir uma bolsa de estudo, decidiu regressar junto a sua mulher, ao Brasil. O estudante também definiu sua experiência com a moradia como tendo sido difícil, no entanto, positiva. Dificil porque ele vinha de uma situação confortável na cidade onde vivia, a casa era própria. Além disso, ele destacou que a convivência "por mais que as pessoas sejam legais, a convivência não é fácil, nem um pouco fácil [...]". Ele e a esposa alugaram um quarto na casa de uma conhecida de uma amiga sua. Era um quarto que não tinha janela, e sua esposa ficava o dia trabalhando no espaço sem janela, enquanto ele saía cedo para a faculdade, todos os dias. Quando Lucas destaca que também foi uma experiência positiva, faz 
referência primeiro à questão das relações, mas também ao ato de aprender a valorizar o próprio espaço. Alice acreditava que quando chegasse a Barcelona conseguiria um trabalho, assim como conseguiu quando se mudou para o Rio de Janeiro: "Não tinha medo", disse ela, em nossa entrevista. Mas quando chegou a Barcelona, percebeu que "as coisas são bem diferentes": "Não imaginava que as pessoas iam me ver tão diferente. Eu era muito ignorante, não sabia como as coisas funcionavam aqui", disse ela na entrevista.

É importante destacar que dos nove estudantes entrevistados, somente dois possuíam uma bolsa de estudo. Esta pode ter sido a razão para a universidade ter sido pouco lembrada, em nossos diálogos. Durante a entrevista com Elvira, ela disse admirar e valorizar as pessoas que faziam doutorado e que, para se manterem na cidade, precisavam trabalhar. Comentou que tinha vários amigos passando pela mesma situação e que por isso sabia o quanto era dificil estudar e trabalhar ao mesmo tempo. Lee (2013) fala de ingenuidade e irresponsabilidade em relação aos modos como a internacionalização é mostrada e logo praticada. Ao tratar de uma possível "falsa aura da internacionalização", Lee (2013, p. 85) comenta o perigo de "promover às cegas a internacionalização sem levar em consideração seus propósitos declarados e consequências imprevistas". As universidades precisam cumprir seu papel em relação às informações que são divulgadas. Seria irresponsável pensar a “internacionalização como algo necessariamente positivo", já que a mesma "não é apenas um conjunto de atividades observáveis", pois envolve tanto responsabilidade social como pedagógica e ética (LEE, 2013, p. 86). Os países e as instituições que recebem os estudantes estrangeiros, assinala a autora, "precisam evitar a exploração de estudantes e estudiosos estrangeiros no interesse do prestígio global ou do retorno econômico. Embora a internacionalização seja parte da paisagem acadêmica de hoje, a forma de praticá-la ainda não foi totalmente definida" (LEE, 2013, p. 85).

\section{A experiência de ser e aprender dos estudantes internacionais}

A experiência de ser estudante brasileiro em Barcelona, as dificuldades, oportunidades e aprendizagens, foram temas de uma das cartas que escrevi na tese, desta vez dedicada aos futuros estudantes brasileiros. Durante os anos em que escrevia a tese, recebia constantemente mensagens de brasileiros pedindo informações relacionadas com a vida cotidiana de um estudante internacional em Barcelona.

Quando estruturava as cartas, seus temas e os destinatários, sempre estavam ao meu lado as entrevistas dos estudantes e suas representações. O que me motivou a escrever tal carta tem a ver, também, com os relatos desses estudantes, suas representações e os modos como o cotidiano de um estudante estrangeiro é construído e posteriormente narrado. Manuais, guias e sites nem sempre tratam daquilo que realmente precisamos saber, quando chegamos a um país que não é o nosso. Eles nos ajudam, nos informam, mas não preveem e não podem antecipar o que se mostra constantemente imprevisível, complexo e múltiplo. É através do cotidiano que podemos ver as múltiplas formas em que os estudantes "produzem artimanhas de reapropriação dos espaços" e como criam, neste caso, "saídas originais para enfrentar os problemas vividos" (FERRAÇO, 2001, p. 96) durante a adaptação ao novo contexto.

Foi nesta carta que trabalhei com o conceito de "aprender". Um conceito chave que nasce quando solicito aos colaboradores que representem sua experiência como estudante internacional através de uma imagem. Para 
Charlot (2000, p. 68), aprendemos porque temos a "oportunidade de aprender, em um momento em que se está, mais ou menos, disponivel para aproveitar essas oportunidades [...]". No entanto, explica o autor, o espaço de aprendizagem é um espaço-tempo com o outro e, por isso, o que está em jogo não é somente “[...] epistémico e didático. Estão em jogo também relações com os outros e relações consigo próprio: quem sou eu, para os outros e para mim mesmo [...] (CHARLOT, 2000, p. 68). Ao compartilharem suas imagens, os colaboradores "narram" o que aprenderam, avaliando, de alguma forma, a relação que construíram com a cidade, com os outros e principalmente consigo mesmos.

As imagens, assim como as histórias, não só nos informam, mas também produzem sentidos que afetam de alguma maneira nossa percepção do mundo e de nós mesmos. Em suas imagens, os estudantes brasileiros falam das dificuldades enfrentadas; de transformação, foco, objetivo; de mistura, de passagem, de descobrimento; de diálogo, equilíbrio, mas de constante deslocamento e principalmente do que aprenderam sobre a experiência de viver/ estar em Barcelona.

Se pudesse escolher uma imagem dos colaboradores, uma que pudesse representar a experiência dos colaboradores da pesquisa, escolheria a imagem de Lucas. Lucas escolheu um trecho de um filme de Theo Angelopoulos, chamado "Paisaje en la Niebla". "¿Tienes miedo? No, no tengo". Voula e Alexandros então correm para entrar no trem, antes que a porta se feche. Eles vão em busca de um pai que não conhecem. Durante a viagem no trem, um homem desconhecido pergunta a eles aonde eles irão, e Alexandros responde: "lejos". Ao descerem do trem, caminham por uma estrada vazia: chove, neva e o clima de solidão toma conta da cena. "Qué mundo más extraño!", disse Alexandros... "maletas, estaciones hela- das, palabras y gestos que no entienden, y la noche que nos da miedo. Pero estamos contentos, avanzamos", finaliza o trecho do filme.

Poderíamos utilizar a metáfora da viagem e, consequentemente, o que levamos dentro da mala, quando decidimos viajar, mas principalmente o que "trazemos" dentro dela, quando retornamos. Onfray diz que "voltar para é também regressar de" (ONFRAY, 2009, p. 99), e, por isso, quando retornamos, fazemos um tipo de balanço, muitas vezes "dominados pela confusão e pela amálgama de sensações, bem como pela incoerência das percepções" (ONFRAY, 2009, p. 100). Alguns dos estudantes compartilharam imagens quando já haviam retornado ao Brasil. Se "voltar é decidir não permanecer", conforme Onfray (2009, p. 101), também é perguntar-se: "O que aprendemos sobre nós próprios, sobre os outros, sobre o mundo?" (ONFRAY, 2009, p. 100).

Durante a entrevista com um dos estudantes, Rodrigo falou sobre os três momentos que caracterizam a viagem: o antes, o durante e o depois. Naquele momento, ele contou sobre o antes e o durante, mesmo que o durante, conforme o estudante, tenha ficado mais claro para ele, após seu retorno. Ele observa "que dependendo da experiência da viagem, entre ser boa ou ruim, fica uma sensação trocada na compreensão dos deslocamentos entre o 'ir' e o 'voltar', afinal", segue ele: "qual a origem e o destino dos lugares por onde passo? Ainda estarei no processo da viagem? Voltarei para algum lugar em definitivo, em algum momento?" Rodrigo destaca que o processo de mudança vivido, de autoconhecer-se através dos deslocamentos, não se iniciou em Barcelona, tampouco terminou depois do seu retorno. No entanto, foi depois de Barcelona que ele pôde confirmar "as possibilidades para o meu livre fluxo entre os lugares e as pessoas", e por isso percebeu (e aprendeu) que: "Nestas andanças, minha capacidade de adaptação ficou mais 
ampla, da mesma maneira que o meu equilíbrio emocional diante de situações que normalmente poderiam ser encaradas com muito medo. Medo devido a instabilidades e incertezas que hoje em dia são inerentes para qualquer ser humano [...]".

É importante destacar que quando os estudantes fazem referência à palavra "aprender", não se referem ao aprender de "objetos-saberes" (CHARLOT, 2000), ou seja, de "objetos aos quais um saber está incorporado: livros, monumentos e obras de arte, programas de televisão 'culturais"' (CHARLOT, 2000, p. 66), mas de um "aprender a ser", que significa "desarollar la persona 'completa', que posee uma mayor autonomia, critério y responsabilidad personal [...], de forma que pueda compreender-se a si mesma y a su mundo, y resolver sus propios

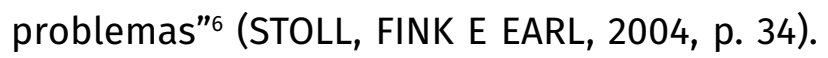
"Aprender a ser", neste sentido, é também “ir siendo, irse haciendo, querer ser, poder ser en relaciones significativas [...] de quien uno va siendo y de quien desea $\operatorname{ser}^{7}$ [...]" (CONTRERAS et al, 2010, p. 57).

Assim, gostaria de encerrar este texto, destacando mais uma vez a importância de debatermos o papel que a internacionalização do ensino superior tem cumprido atualmente no mundo. Que possamos criar ou ampliar os espaços de diálogo e escuta daqueles que mais sofrem seu impacto, os estudantes internacionais. Que os relatos e as experiências de ser possam se contrapor aos dados estatísticos e que o conhecimento, seja ele científico, emocional ou social, nos ensine mais sobre o ir e vir daqueles que têm transitado pelo mundo.

6 'desenvolver a pessoa 'completa', que possui uma maior autonomia, critério e responsabilidade pessoal [...], para que ela possa entender a si mesmo e seu mundo e resolver seus próprios problemas".

7 "sendo, tornando-se, querer ser, poder ser em relações significativas [...] de quem um está sendo e de quem deseja ser".

\section{Referências}

ALTBACH, Philip. Globalisation and the University: Myths and Realities in an Unequal World. Tertiary Education and Management, 10, p. 3-25, 2004.

ALTBACH, Philip; KNIGHT, Jane. The internalization of higher education: motivations and realities. Journal of Studies in Internalization of Education, 11, 3(4), 290-305, 2007.

ALTBACH, Philip; REISBERG, Liz; RUMBLEY, Laura (2009). Trends in Global Higher Education, Tracking an Academic Revolution. Paris: UNESCO, 2009.

BAUMAN, Zigmunt. Confianza y temor en la ciudad vivir con extranjeros. Barcelona: Arcadia, 2006.

BOLIVAR, Antonio; DOMINGO, Jésus; FERNÁNDEZ, Manuel. La investigación biográfico-narrativa en educación: enfoque y metodología. Madrid: Editorial La Muralla, 2011.

BRUNER, Jerome. Actual minds, possible worlds. Cambridge: Harvard. University Press, 1986.

BRUNER, Jerome. Actos de significado: más allá de la revolución cognitiva. Madrid: Editorial Alianza, 2006.

CAHNMANN-TAYLOR, Melisa; SIEGESMUND, Richard. Arts-based research in Education. Foundations for practice. New York: Routledge, 2008.

CHARLOT, Bernard. Da relação com o saber. Elementos para uma teoria. Porto Alegre: Artmed, 2000.

CONNELLY, Michael; CLANDININ, Jean. Relatos de experiencia e investigación narrativa. In: LARROSA, Jorge (Ed.). Déjame que te cuente. Ensayos sobre narrativa y educación. Barcelona: Laertes, 1995. p. 11-59.

CONTRERAS et al. Entre ser e saber. La formación de la subjetividad en la escuela Sant Josep. In: HERNÁNDEZ, Fernando; MONTSERRAT, Rifá. (Eds.). Aprender a ser en la escuela primaria. Barcelona, Octaedro, 2010. p. 57-97.

DE WIT, Hans. Internationalisation of Higher Education in Europe and Its Assessment, 
Trends and Issues. De Nederlands-Vlaamse Accreditatieorganisatie (NVAO), 2010. Disponivel em:<http://www.nvao.net/page/downloads/ Internationalisation_of_Higher_Education_in_ Europe_DEF_december_2010.pdf> Acessado em: 11 jun. /06/2014.

DE WIT, Hans. Repensando o conceito de internacionalização. Revista Ensino Superior Unicamp, 70, p. 69-71, 2013. Disponivel em: < https:// www.revistaensinosuperior.gr.unicamp.br/edicoes/ ihe/IHE70port.pdf>. Acesso em: 10 mar. 2013.

FERRAÇO, Carlos Eduardo. Ensaio de uma metodologia efêmera: ou sobre as várias maneiras de se sentir e inventar o cotidiano escolar. In: OLIVEIRA, I. B.; ALVES, N. (Org.). Pesquisa no/do cotidiano das escolas: sobre redes de saberes. Rio de Janeiro: DP\&A, 2001. p. 91-108.

FISCHER, Rosa Maria Bueno. Escrita Acadêmica: a arte de assinar o que se lê. In: COSTA, Marisa; BUJES, Maria. (Eds.). Caminhos Investigativos III. Riscos e possibilidades de pesquisar nas fronteiras. Rio de Janeiro: DP\&A, 2005. p. 117-140.

FOUCAULT, Michel. 0 que é um autor? Lisboa: Vega, 1992.

GAZZOLA, Ana Lucia Almeida. Conhecimento e globalização. In: GAZZOLA, Ana Lucia Almeida; ALMEIDA, Sandra Goulart. (Eds.). Universidade: cooperação internacional e diversidade. Belo Horizonte: Editora UFMG, 2006. p. 49-55.

GIDDENS, Anthony. Las consecuencias de la modernidad. Madrid: Alianza Editorial, 2008.

GUATARRI, Felix; ROLNIK, Suely. Micropolítica: cartografias do desejo. Petrópolis, RJ: Editora Vozes, 2011.

HELLSTÉN, Meeri. International student transition: focusing on researching internacional pedagogy for educational sustainability. The International Educational Journal: comparative perspectives, 8 (3), 79-89, 2007.

HELLSTÉN, Meeri. Researching International Pedagogy and the Forming of New Academic Identities. In: HELLSTÉN, Meeri; REID, Anne. (Eds.).
Researching International Pedagogies: Sustainable Practice for Teaching and Learning in Higher Education. Netherlands: Springer, 2008. p. 83-99.

HELLSTÉN, Meeri; REID, Anne. (Orgs.). Researching international pedagogies: Sustainable practice for teaching and learning in higher education. Netherlands: Springer, 2008.

HELLSTÉN, Meeri; UCKER PEROTTO, Lilian. Re-thinking internationalization as social curriculum for generative supervision: letters from the international community of scholars, European Journal of Higher Education, $v$. 8, 2018 - Issue 1, p. 1-17, 2017.

HERNÁNDEZ, Fernando; RIFÁ, Montse. (Orgs.). Investigación autobiográfica y cambio social. Barcelona: Octaedro, 2011.

HERNÁNDEZ, Fernando. (Org.). Aprender a ser en la escuela primaria. Barcelona: Paidós, 2010.

IONTA, Marilda. A escrita de si como prática de uma literatura menor: cartas de Anita Malfatti a Mário de Andrade. Estudos Feministas, Florianópolis, 91-101, 2011. Disponivel em: <http://www.scielo.br/scielo. php?pid=S0104-026X2011000100007\&script $=$ sci abstract\&tlng=pt>. Acesso em: 20 dez. 2012.

KNIGHT, Jane. Cinco verdades a respeito da internacionalização. Revista de Ensino Superior, Unicamp, 2012. Disponivel em: <http:// www.revistaensinosuperior.gr.unicamp.br/ internationalhigher-education/cinco-verdades-arespeito-da-internacionalizacao>. Acesso em: 24 abr. 2013.

LEE, Jenny. A falsa aura da internacionalização. Revista de Ensino Superior Unicamp, n. 71, p. 85-87, 2013. Disponível em: <www.revistaensinosuperior. gr.unicamp.br/edicoes/ihe/IHE72port.pdf>. Acesso em: 10 mar. 2013.

LIMA, Manolita Lima; CONTEL, Fabio Betioli. Internacionalização da educação superior. Nações ativas, nações passivas e a geopolítica do conhecimento. São Paulo: Alameda, 2011.

LUCE-KLAPER, Rebecca. Writing with, through and beyond the text - An ecology of language. Mahwah, NJ: Lawrence Erlbaum, 2004. 
MACHADO, Leila Domingos. O desafio ético da escrita. Psicologia e Sociedade, 16 (1), Porto Alegre, 2004. Disponível em: <doi http://dx.doi.org/10.1590/ S0102- 71822004000100012>. Acesso em: 14 fev. 2013.

MELLO, Alex Fiuza. Globalização, sociedade do conhecimento e educação superior. Os sinais de Bolonha e os desafios do Brasil e da América Latina. Brasília, DF: Editora da UnB, 2011.

NÓVOA, António. Textos, imágenes y recuerdos. Escritura de 'nuevas' historias de la educación. In: POPKEWITZ, T., FRANKLIN, B.; PEREYRA, M. (Orgs.). Historia cultural y educación. Ensayos críticos sobre conocimiento y escolarización. Barcelona: Pomares Corredor, 2003. p. 61-101.

ONFRAY, Michel. Teoria da viagem: uma poética da Geografia. Lisboa: Quetzal Editores, 2009.

PINNEGAR, Stefinne; DAYNES, Gary. Locating narrative inquiry historically: Thematics in the turn to narrative. In: CLANDININ, Jean. (Ed.). Handbook of narrative research. Mapping a methodology. Thousand Oaks, CA.: Sage, 2007. p. 3-34.

PORRES, Alfred. Relaciones pedagógicas en torno a la cultura visual de los jóvenes. Barcelona: Ediciones
Octaedro, 2012.

RIBEIRO, Neurilene Martins; SOUZA, Elizeu Clementino de. As cartas e as histórias de vida: dilemas e aprendizagens da docência em língua portuguesa. In: OLIVEIRA, Inês Barbosa. (Org.). Narrativas: outros conhecimentos, outras formas de expressão. Rio de Janeiro: FAPERJ, 2010. p. 79-97.

STOLL, Louise; FINK, Dean; EARL, Lorna. Sobre el aprender y el tiempo que requiere: implicaciones para la escuela. Barcelona: Ediciones Octaedro, S.L, 2004.

UCKER, Lilian. Espaços reais e imaginados: um estudo de desenhos de alunos em escolas públicas de Goiânia. 2006. 217 f. Dissertação (Mestrado em Cultura Visual) - Programa de Pós-Graduação em Arte e Cultura Visual, Universidade Federal de Goiás, Goiânia, 2006.

WALKER, John; CHAPLIN, Sarah. Una introducción a la cultura visual. Barcelona: Octaedro, 2002.

Recebido em: 30.11.2017

Aprovado em: 21.02.2018

Lilian Ucker Perotto é Professora Adjunta da Faculdade de Artes Visuais (FAV-UFG). Doutora em Arte-Educação pela Universidade de Barcelona (Espanha). Mestre em Cultura Visual (UFG). Licenciada e Bacharel em Artes Visuais (UFSM). e-mail: lilianucker@gmail.com

Rua 52, 1056. Edifício Visage Arena, apt 2402. Setor Jardim Goiás. Goiânia/GO. CEP: 74810-200. Telefone: (62) 98159-4868 